\title{
OS IMPACTOS DA BASE NACIONAL COMUM CURRICULAR NA CONSTRUÇÃO DO CURRÍCULO PIRACICABANO
}

\author{
Eduardo Fernando FRANCINI ${ }^{i}$ \\ Maria Alejandra MORENO-PIZANI ${ }^{i i}$
}

\begin{abstract}
RESUMO
A BNCC para Educação Infantil e Ensino Fundamental foi homologada em 2017 e, com os currículos locais, está sendo implantada nas escolas em 2020. Nossa pergunta principal é: quais os impactos da implantação de uma matriz única para a Educação Básica no contexto local piracicabano? No papel de colaborador externo, acompanhamos os debates promovidos pela Secretaria Municipal de Educação (SME) que culminaram na elaboração de um currículo para os quase trinta e sete mil alunos da rede. Os efeitos observados constituíram-se novos paradigmas na construção curricular, tendo o aluno (suas habilidades e atitudes) e a resolução de problemas (competências) como centralidade da ação educativa. Aos gestores cabe otimizar o processo de implantação com o uso de tecnologias, alocando recursos de forma eficiente e, principalmente, cuidando das pessoas, dos professores protagonistas que concretizarão tal currículo.
\end{abstract}

PALAVRAS-CHAVE: Política pública educacional; BNCC; Currículo; Gestão escolar.

\section{THE IMPACTS OF THE BRAZILIAN COMMON CORE IN THE CONSTRUCTION OF THE CURRICULUM FOR THE CITY OF PIRACICABA SÃO PAULO BRAZIL}

\begin{abstract}
The BNCC for Early Childhood Education and Elementary Education was approved in 2017 and, along with the local curricula, is being implemented in schools in 2020. Our main question is: what are the impacts of the implementation of a single matrix for Basic Education in the local context of Piracicaba? In the role of external collaborator, we follow the debates promoted by the municipality board of education (SME) that culminated in the elaboration of a curriculum for almost thirty-seven thousand students. The observed impacts were constituted in new paradigms in the curriculum construction with the student (their skills and attitudes) and problem solving (competences) as the centrality of the educational action. School administrators are responsible for optimizing the implementation process using technologies, allocating resources efficiently and, mainly, taking care of the people, of the protagonist teachers who will materialize such curriculum.
\end{abstract}

KEYWORDS: Educational public policy, BNCC, Curriculum, School administration.

\footnotetext{
${ }^{\text {i } M e s t r a n d o ~ e m ~ L i n g u i ́ s t i c a ~ A p l i c a d a ~ n a ~ U n i v e r s i d a d e ~ E s t a d u a l ~ d e ~ C a m p i n a s ~ e ~ p o ́ s-g r a d u a d o ~ n o ~ M B A ~ d e ~ G e s t a ̃ o ~}$ Escolar da Universidade de São Paulo / Pecege. E-mail: eduardo.f.francini@gmail.com.

ii Doutorado em Engenheira de Sistemas Agrícolas pela Escola Superior de Agricultura "Luiz de Queiroz" da Universidade de São Paulo. Professora na Faculdade Pecege. E-mail: mariapizani@pecege.com.
} 


\section{LOS IMPACTOS DE LA MATRIZ CURRICULAR BRASILEÑA EN LA CONSTRUCCIÓN DEL PROGRAMA DE ESTUDIOS DE LA CIUDAD DE PIRACICABA SÃO PAULO BRASIL}

\section{RESUMEN}

La BNCC para la educación infantil y la educación primaria fue aprobada en 2017 y, junto con los programas de estudios locales, se está aplicando en las escuelas en 2020. Nuestra principal pregunta es: ¿cuáles son los efectos de la aplicación de una matriz única para la educación básica en el contexto local de Piracicaba? En el papel de colaborador externo, seguimos los debates promovidos por la Secretaria Municipal de Educación (SME) que concluyeron en la elaboración de un plan de estudios para casi treinta y siete mil alumnos. Los impactos observados se constituyeron en nuevos paradigmas en la construcción del currículo con el estudiante (sus habilidades y actitudes) y la resolución de problemas (competencias) como la centralidad de la acción educativa. Los administradores de las escuelas son responsables de optimizar el proceso de implementación utilizando tecnologías, asignando recursos de manera eficiente $y$, principalmente, cuidando de las personas, de los profesores protagonistas que materializarán dicho currículo.

PALABRAS CLAVE: Política Pública Educativa, BNCC, Currículo, Gestión Escolar.

\section{INTRODUÇÃO}

Elaborar políticas públicas educacionais no Brasil implica lidar com desigualdades históricas e realidades tão vastas quanto o próprio País. Com esse entendimento, o escopo ora proposto indicou três extensões de atuação da pesquisa: o currículo piracicabano, que amplia as aprendizagens essenciais dispostas na Base Nacional Comum Curricular (BNCC), a própria BNCC para Educação Infantil e Ensino Fundamental, homologada em dezembro de 2017, e os pactos entre os entes federativos para que as mudanças pretendidas se reflitam nos Projetos Políticos Pedagógicos (PPP) das escolas e nos planos de aulas dos professores. O ineditismo de uma matriz nacional normativa exige atenção da academia para o acompanhamento das práxis.

Tomando a Constituição e o Plano Nacional de Educação (PNE), observamos que um objetivo comumente explicitado em ambos é a organização de matriz nacional com as expectativas mínimas - ou essenciais, como aponta o documento - de aprendizagem para os segmentos da Educação Básica. Em abril de 2017, após pouco mais de dois anos intensos de debates e duas versões anteriores, o Ministério da Educação entrega ao Conselho Nacional de Educação (CNE) a BNCC.

$\mathrm{Na}$ linha das recentes reformas educacionais fomentadas por forças classificadas por Freitas (2014) como reformadores empresariais da educação, a BNCC apresenta-se mais como uma matriz que estabelece objetivos mínimos de aprendizagem para avaliação em larga escala. 
Conforme aponta o autor, as avaliações externas orientam e determinam os currículos por meio de objetivos de aprendizagem observáveis e mensuráveis. Ao entendermos essa corrente de pensamento e cientes de um possível retorno tecnicista do próprio propósito da educação formal, é imprescindível contextualizarmos a lógica empresarial subjacente ao que comumente se chama, hoje, de educação para o século XXI.

Os novos currículos com o selo "de acordo com a BNCC" seguem a diretiva da educação integral, ou seja, estabelecem - além do rol das competências cognitivas - descritores para competências socioemocionais que orientam os valores, as atitudes e as disposições esperados dos alunos. Ao fim da educação integral, deseja-se que o aluno tenha as ferramentas necessárias para construir seu projeto de vida. Essa primeira reflexão é essencial para compreendermos o ressurgimento de uma proposta instrumentalizadora defendida por Dewey (1959).

As variadas visões sobre o desenvolvimento da criança também regulam as diferentes práticas e as diversas produções teóricas que fundamentam as políticas educacionais. Davis e Oliveira (1994), ao classificarem essas visões sobre a criança, apontam grupos antagônicos, por exemplo, os que consideram a criança um ser que nasce previamente formado e os que entendem a formação da criança a partir da ação do ambiente social e natural em que se encontra. Nesse último grupo, os estudos de Vygotsky estabelecem a importância da interação social, historicamente determinada pelas e nas sociedades, para o desenvolvimento infantil. Para esse autor, a interação social é o espaço de constituição e desenvolvimento da consciência no ser humano, desde que nasce. Pensar, pois, em um currículo significaria propiciar intencionalmente processos nos quais a criança adquira níveis progressivos de complexidade em pensamento, emoção, ação e interação.

A suposição de que escolas e profissionais da educação estejam preparados para realizar as mediações necessárias entre princípios gerais da educação e práticas cotidianas está presente na orientação de que as unidades de Educação Básica devem elaborar seus próprios planos pedagógicos, justificando suas metas e propostas para cada ano letivo. As pesquisas que têm procurado avaliar amostras desses planos, entretanto, revelam a precariedade geral e até a inexistência dos PPP, de forma análoga ao que verificaram alguns levantamentos sobre currículos municipais (a cidade de Piracicaba, por exemplo, não dispunha de um currículo local até dezembro de 2019). 
Por conseguinte, a nosso ver, é evidente o foco no desenvolvimento dos profissionais da educação em serviço, uma vez que eles farão a implantação do instrumento de política pública educacional na ponta do sistema. Tal desenvolvimento tem escopo abrangente: requer desde discussões sobre os entendimentos dos docentes e gestores educacionais acerca dos propósitos da educação formal até chegar a modelos didático-metodológicos que se adéquam aos novos objetos de conhecimento. Na prática, percebemos oficinas de formação teórica sobre competências e habilidades e metodologias ativas, com forte influência das ideias do sociólogo suíço Philippe Perrenoud e do professor-pesquisador José Moran.

Buscamos por referenciais teóricos que validam - ou refutam - as ideias levantadas a partir da pesquisa exploratória da BNCC e dos novos currículos escolares. Interessaram-nos, de modo geral, os novos currículos que florescem de tal matriz singular. Analisamos suas estruturas, recortes e escolhas para traçar diálogos com as demandas das sociedades e das representatividades educacionais do País. Em específico, perpetramos: A) o mapeamento das políticas públicas que aludem à criação de uma matriz curricular nacional de ensino e o currículo municipal que surge a partir dela; B) a análise da BNCC para Educação Infantil e Ensino Fundamental, em sua constituição teórica e histórica; e C) a identificação de fatores de impacto na adequação curricular e na rotina escolar de uma rede municipal de ensino.

\section{MATERIAL E MÉTODOS}

Muito do que se reflete hoje sobre currículo nasceu de estudos críticos americanos a respeito do tema na década de 1960. Silva (1999, p. 32), em Documentos de identidade: uma introdução às teorias do currículo, realça a importância dos estudos de Louis Althusser, segundo o qual "a escola contribui para a reprodução da sociedade capitalista ao transmitir, através das matérias escolares, as crenças que nos fazem vê-la como boa e desejável”.

No Brasil, Paulo Freire sintetizou suas críticas sobre o que denominava educação bancária e defendia que no País pudesse se conceber o currículo como um ato dialógico no qual educadores e educandos participariam da escolha de seus conteúdos. Diferentemente do contexto americano, a situação pós-ditatorial brasileira fez surgir a necessidade de uma pedagogia que desse voz ao que foi censurado e marginalizado. Assim, pensar em currículo na perspectiva da Pedagogia do Oprimido significava fortemente incluir processos libertários e 
emancipatórios. Essa mudança de foco curricular foi a posteriori criticada por Demerval Saviani, justificando que a pedagogia pós-colonialista proposta por Freire não enfatizava a aquisição do saber. Segundo Saviani (1983), o conhecimento é poder e, por isso, crucial para a emancipação dos grupos marginalizados.

As contribuições de Saviani alinham-se às pesquisas internacionais da época para afirmar que a educação no Brasil, principalmente no que dizia respeito às crenças de escolarização para crianças pequenas, não deveria preocupar-se apenas com o cuidado e o acolhimento social, mas igualmente com um currículo rigoroso na apresentação de conteúdos e procedimentos nas diversas áreas de produção científica e cultural.

Ainda como herança estruturalista curricular americana, a proposta defendida no Brasil a partir das décadas de 1980 e 1990 culminou por criar sistemas de avaliações nacionais de aprendizagem que revelaram o insucesso das instituições no País. Importa registrarmos esse tópico, uma vez que se acusa o caráter avaliacionista da Base para fins de promoção de políticas de equidade, nivelando minimamente por baixo os conhecimentos de letramento e "numeramento" (do inglês, literacy e numeracy).

Para além do "ler e escrever", Apple (1982) descreve um conjunto de normas e valores implícitos e efetivamente transmitidos pela escola, embora não constem dos fins e objetivos programados pelos professores: o currículo oculto. Se pensarmos o currículo como a reordenação de discursos de grupos sociais dominantes, o currículo oculto é a própria projeção velada não só das crenças, mas também das expectativas sociais com relação aos objetivos da educação. Exemplos fortes de processo recorrente, mas não explicitado, nas legislações do currículo velado brasileiro são a discriminação e a seletividade. É aquela máxima que todos sabem, mas contra a qual nada se faz, quando, eventualmente, um professor diz "Estuda isso porque cai no vestibular", ou então quando das séries iniciais confunde-se a ludicidade intencional com o brincar por si só.

O currículo, para ser, portanto, orientador das práticas, deve ser encarado como instrumento de planejamento e gestão pedagógica, materializando-se em um documento de fácil leitura, claro e objetivo, a partir do qual todas as ações educativas devem ser pensadas. Nesse sentido, a BNCC, como afirma o próprio Instituto Nacional de Pesquisa Anísio Teixeira (INEP), não é currículo. A Base é uma referência nacional obrigatória, que deve orientar os currículos dos estados e municípios ao propor os objetivos que se esperam dos estudantes. 
Na contramão dessa política brasileira, na Finlândia, a autonomia permeia desde o currículo até o trabalho do professor, que pode decidir por sua conta como avaliar os alunos ou que métodos e materiais usar em sala de aula. Por trás dessa concepção está a ideia de que ninguém melhor do que o professor para conhecer os pontos fortes e fracos de sua turma e orientá-la. Naquele país, não se espera que as crianças sejam capazes de ler e escrever antes dos sete anos. A educação na primeira infância e pré-primária é desenvolvida por meio de competências de aprendizagem e habilidades sociais, como trabalhar em grupos, expressar-se, ter boas maneiras, hábitos saudáveis etc.

Ao avaliar a proposta de criação de uma base nacional comum, Macedo (2014) critica esse tipo de matriz por criar a regulação do processo educativo baseada na avaliação, segundo modelos privados de gestão. Esse importante debate acerca do que deve ser comum em uma base nacional é apresentado no texto que introduz a Base. A BNCC e os currículos se identificam na comunhão de princípios e valores oriundos da Lei de Diretrizes e Bases e das Diretrizes Curriculares Nacionais: compromisso com a formação e o desenvolvimento humano global, em suas dimensões intelectual, física, afetiva, social, ética, moral e simbólica. Além disso, BNCC e currículos têm papéis complementares para assegurar as aprendizagens essenciais definidas para cada etapa da Educação Básica, uma vez que tais aprendizagens só se materializam mediante o conjunto de decisões que caracterizam o currículo em ação.

Conforme descrito na BNCC, nas páginas 13 e 14 de sua versão final, cabe aos sistemas e redes de ensino, assim como às escolas, em suas respectivas esferas de autonomia e competência, incorporar aos currículos e às propostas pedagógicas a abordagem de temas contemporâneos que afetam a vida humana em escala local, regional e global, preferencialmente de forma transversal e integradora.

Em lugar de um currículo prescrito, argumentamos, a opção deveria ser um trabalho mais desestruturado, pautado pelos interesses e pelas culturas infantis, de forma livre e criativa. Numa direção oposta, a Base prescreve conteúdos, habilidades e comportamentos considerados necessários para a vida no século XXI.

Laboramos a análise documental-bibliográfica para discutir a organização de uma matriz curricular nacional para Educação Básica e os arranjos de sua implantação por meio dos currículos das redes, em particular do estado de São Paulo e da cidade de Piracicaba. Pimentel (2001) afirma que pesquisas dessa natureza são desenvolvidas por meio de documentos, 
contemporâneos ou retrospectivos, e têm sido amplamente utilizadas com a finalidade de descrever e/ou comparar fatos sociais, estabelecendo suas características e tendências. Assim, traçaremos um histórico crítico da literatura nos campos do desenvolvimento da aprendizagem e de currículo para ilustrar as tendências nas áreas.

Numa época em que as reformas educacionais estão em evidência, a metodologia ora escolhida interessa-se por buscar paradigmas, i.e., referenciais teóricos, que validam - ou refutam - as ideias levantadas a partir da pesquisa exploratória. Essa análise imprime, além da revisão literária por meio de pesquisa bibliográfica, a necessidade de levantar conjecturas sobre seu preito e efeito nos diversos contextos de educação formal.

A pesquisa também considerou a participação do pesquisador como colaborador externo nos encontros da Secretaria Municipal de Educação (SME), com coordenadoras, supervisoras e gestores da rede municipal, com o objetivo de estudar a BNCC e o currículo paulista (CP) e com a missão visionária de construir o currículo local.

Ao longo dos três últimos anos, a rede municipal promoveu encontros formativos acerca das premissas que organizam a Base (competências, habilidades, direitos de aprendizagem, campos de experiência etc.). As formações aconteceram tanto em momentos previstos nos Horários de Trabalho Pedagógico Coletivo (HTPC) quanto em horários extras. A cidade sediou, ainda, um seminário com foco no estudo do Currículo Paulista enquanto se preparava para redigir a primeira versão do próprio currículo municipal, homologado pelo prefeito em dezembro de 2019.

\section{RESULTADOS}

Uma concepção comum de currículo é a de que ele se refere aos tópicos estudados no período de escolarização formal. Contudo, a visão trazida pela matriz nacional e pelo currículo municipal ultrapassa essa ideia limitada de rol de conteúdos, incluindo as vivências de todos os envolvidos nas decisões e adaptações que promovam as aprendizagens. É, portanto, constituído organicamente, no coletivo com intencionalidade.

Um segundo paradigma que encontramos em nossas análises é a mudança de foco: do conteúdo e suas implicações teóricas para o aluno e seu viés de uso na resolução de problemas. Perceber as crianças como exploradores de seus mundos significa incluí-las no centro das ações 
pedagógicas, com didáticas (metodologias) ativas que beneficiam a natureza construtivista do conhecimento, de maneira social, interativa e integradora. Isso implica, por fim, a definição do que se entende por aluno e para qual finalidade formativa serve a instituição educacional pública.

Esses dois paradigmas - a saber, a relocalização dos saberes e a centralidade nas práticas discentes - configuram propostas audaciosas e absolutamente necessárias para o agenciamento crítico e a emancipação dos sujeitos. Tal visão se contrapõe à tradicional monocultura do conhecimento que invisibiliza outros saberes e culturas marginalizados por uma minoritária cultura hegemônica financiada pelo capital. O sociólogo português Santos (2006) caracteriza como ecologia dos saberes essa consideração da pluralidade dos conhecimentos e das diversas formas com que são mobilizados para criar ações. Uma epistemologia que deve emergir e se sustentar para uma globalização não hegemônica, considerando o global e o local, é a reflexão sobre as práticas de saberes e seus impactos nas práticas sociais.

Na mesma linha, o Regimento Comum das Escolas Municipais de Piracicaba (RCEMP), em seu Capítulo IV, artigo 8. $^{\circ}$, define que a educação no município tem por meta a formação do aluno como agente do processo de construção do conhecimento e da transformação das relações sociais, tendo em vista a formação de uma consciência social crítica, solidária e democrática. Essa concepção do propósito dos atos educativos é aprofundada nos objetivos da Educação Infantil e do Ensino Fundamental em proporcionar condições adequadas de desenvolvimento físico, emocional, cognitivo e social da criança e promover a ampliação de suas experiências e conhecimentos, estimulando seu interesse pelo processo de transformação da natureza e pela convivência em sociedade, por meio da interação com a função social da escrita, construindo e ampliando seus conhecimentos, criando situações em que possa manifestar seu pensamento por meio de atividades de troca, experimentação e observação que estimulem seu raciocínio, curiosidade e crítica.

Especificamente sobre os objetos do conhecimento, o RCEMP privilegia garantir aos alunos a apropriação de conhecimentos básicos, sistematizados e significativos, incorporando suas experiências sociais e culturais, num processo de ampliação de sua capacidade de elaboração, compreensão e representação da realidade na perspectiva de transformá-la.

Considerando, pois, tais objetivos, em concordância com o Plano Nacional de Educação, a SME redigiu o Plano Municipal de Educação (PME) para o decênio 2016-2026, aprovado 
pela Lei Municipal 8.501/2016, metas para a rede, entre as quais destacamos: a erradicação do analfabetismo, a universalização do atendimento escolar, a promoção do princípio da gestão democrática da educação e a valorização dos profissionais da educação.

Em 2017, com a alteração da LDB pela Lei 13.415/2017, e a partir da homologação da BNCC, a rede municipal iniciou uma reflexão crítica sobre o currículo local de modo a assegurar os princípios propostos para o município, alinhando e ampliando os direitos e os objetivos de aprendizagem explicitados na matriz nacional com competências e habilidades desejáveis para a vida e para o trabalho no século XXI.

Vivenciamos um momento crucial de definições curriculares; pensar em um currículo de relevância local visando à formação de um cidadão global implica escolhas necessárias para enfrentamento dos problemas que a realidade apresenta e para um futuro incerto. E, nessa perspectiva, o currículo é orgânico, ele é a própria escola em seu propósito educativo, que é a formação do sujeito crítico, autônomo e empático na construção de seu projeto de vida.

Como resultado prático, elencaram-se os seguintes elementos como princípios norteadores do currículo:

$>$ o ideal de cidadão que se pretende formar;

$>$ os conhecimentos, as competências e as habilidades estabelecidos pela BNCC e pelo CP;

$>$ os conhecimentos, as competências e as habilidades estabelecidos pela própria rede e suas comunidades, suplementares e complementares aos da Base e aos do CP;

$>$ a equidade; $\mathrm{e}$

$>$ a excelência acadêmica.

É importante ressaltar a preocupação com a formação integral da criança, explicitada no RCEMP no início deste texto. Assim, o item (i) dos elementos supracitados é o ponto de partida para as reflexões. Os itens (iv) e (v) estão inseridos em um escopo maior de compromisso do munícipio, explicitados no PME e cuja mensuração vem ocorrendo de maneira sistemática e transparente ${ }^{1}$. Os itens (ii) e (iii) concentram os maiores esforços no desenho curricular, uma vez que estão relacionados diretamente com as práticas pedagógicas.

Aqui vale uma reflexão a respeito do princípio da excelência acadêmica. No contexto da Educação Básica, no qual o município está inserido, a excelência acadêmica é aferida quase que exclusivamente pelo Índice de Desenvolvimento da Educação Básica ${ }^{2}$ (Ideb) a partir da 
combinação entre o resultado obtido pelos alunos em exames padronizados do Sistema de Avaliação da Educação Básica (SAEB) e a taxa de aprovação, indicador que tem influência na eficiência do fluxo escolar. Sem nos prolongarmos muito sobre as falácias a que os testes padronizados podem nos induzir, ressaltamos que o município de Piracicaba tem Ideb de 6,8 (valores médios de 2017), índice superior às médias do Brasil e do estado de São Paulo, o que coloca os alunos no nível Proficiente na escala, indicando avanços na competência leitora e na compreensão de conteúdos.

Todos os avanços aconteceram mesmo sem a cidade possuir um currículo sistematizado, embora tenha práticas integradoras e comuns propostas por outros documentos legais. Futuramente, um novo estudo será necessário para perceber os efeitos da implantação do currículo municipal nos testes padronizados, incluindo um novo sistema de avaliação da Educação Infantil, inédito no País e ainda em elaboração pelo Ministério da Educação e Cultura (MEC). Os novos testes do Saeb deverão aferir as competências e habilidades da BNCC e, por comparação, como o currículo municipal apropriou-se delas.

A BNCC não é um currículo; essa matriz nacional deve orientar os currículos dos sistemas e redes de ensino, como também as propostas pedagógicas de todas as escolas públicas e privadas. Compreendendo essa diretriz, a rede municipal conseguiu adir aos conhecimentos, às competências e às habilidades mínimas estipulados seus anseios locais, com base nas características das comunidades educativas a que serve. Ademais, o município entende que a criança é ativa no processo de aprendizagem e deve ser encorajada a assumir uma atitude participativa, ética e responsável nas vivências escolares. E aqui não se trata apenas de "empoderar" os alunos - são vivências que estimulam a criatividade, a criticidade e a autonomia das crianças, valorizando suas culturas, incentivando o aprender a aprender e promovendo altas expectativas com relação aos seus desempenhos.

De maneira pragmática, o currículo materializa-se por um rol de objetivos de aprendizagens que devem ser redigidos de maneira clara, direta, e caracterizados por duas premissas fundamentais: devem ser observáveis e mensuráveis. Não obstante os direitos de aprendizagem, as competências gerais, os campos de experiências e os componentes curriculares privilegiados na BNCC, as habilidades das competências leitora, escrita e de raciocínio lógico-matemático permeiam o currículo de todas as modalidades. Conforme lê-se no Documento Curricular da Rede Municipal de Ensino de Sobral ${ }^{3}$, considerado um exemplo 
de matriz curricular nacional, a prioridade educacional formal é a ênfase no desenvolvimento pleno das habilidades de leitura, escrita e raciocínio lógico-matemático - uma decisão cada vez mais comum nas reformas educacionais de países desenvolvidos que aspiram a excelência e a equidade no oferecimento de oportunidades de aprendizagem às suas populações. Decorre da percepção de que esse instrumental de compreensão e prática competente das linguagens alfabética e matemática é essencial para o domínio de vastas áreas do conhecimento, como História e demais humanidades e Ciências, por exemplo, e para desenvolver a autonomia dos alunos na aquisição e produção de conhecimento no futuro. Assim, as reformas educacionais recentes dos países desenvolvidos vêm dando cada vez maior ênfase aos esforços para aperfeiçoar nos alunos, em um patamar bem mais alto de complexidade e sofisticação cognitiva, capacidades de uso hábil das linguagens alfabética e matemática como ferramentas para se aprimorar pessoal, acadêmica e profissionalmente ao longo da vida, a partir das quais todas as demais disciplinas e desafios são mais facilmente abordados.

A matriz de referência curricular nacional busca atribuir sentido às práticas escolares centrando-se em competências desejáveis. Longe de trazer para esse âmbito a polêmica que envolve essa afirmação e cientes de que somos das críticas da pedagogia histórico-crítica ao modelo de base curricular por competência, ressaltamos que o currículo do estado de São Paulo também carrega uma concepção de ensino - e aprendizagem - que parte da definição de competências e da análise de situações, recorrendo aos componentes curriculares na medida das necessidades exigidas pelo desenvolvimento das competências, em vez de partir de um corpo de conteúdos clássicos existente.

Nesse sentido, o aluno é entendido como um indivíduo que articula uma série de tarefas em diversos campos de atuação. Esse caráter pragmaticista pode reduzir ou empobrecer as práticas de ensino, se focadas apenas no cumprimento de tarefas, ou na realização de atividades que aplicam esquemas operatórios. Antes, a proposta da BNCC, seguida também pelo CP, implica deixar de fazer a separação entre o conhecimento e o saber-fazer para centrar o esforço em resultados de aprendizagem nos quais se atinge uma integração entre ambos.

Tal como sua referência curricular (que é a BNCC), o CP tem como princípio norteador uma proposta de Educação Integral para além de apresentar um conjunto de conteúdos, habilidades e objetivos de aprendizagem e desenvolvimento. O texto introdutório da guia curricular ilustra a intenção de promover orientações para integração curricular, meios para 
melhorar as relações humanas e o desenvolvimento de projeto de vida. Nesse sentido, e pela própria natureza do que se pretende como currículo, novas configurações aparecem no documento paulista, seguidas também pelo currículo de Piracicaba.

Uma dessas configurações, em especial, ganha destaque na escrita, embora ainda bastante enxuta ao tentar explicitar suas formas - trata-se da aprendizagem cooperativa, tanto no contexto do ensino e aprendizagem quanto no campo da formação docente. Outro ponto que merece destaque é o trabalho com multiletramentos a partir da referência cultural dos estudantes, das mídias e linguagens conhecidas em seu contexto, com o objetivo de fomentar a crítica, a pluralidade e a ética, e com o uso de tecnologias digitais que exigem novos letramentos.

As diretrizes nacionais para redação de um currículo para os sistemas de ensino preveem que o desenho curricular do município contemple, mas não se limite, à Base Comum. Portanto, ao redigir o documento, a visão de educação da SME deve ser explicitada logo de início, uma vez que está absolutamente alinhada com as Competências Gerais e os Direitos de Aprendizagem dispostos na BNCC. Outrossim, as habilidades derivadas dos Campos de Experiência e dos Eixos serão as expectativas de aprendizagem mínimas para o currículo da rede, sendo ampliadas e aprofundadas pelas necessidades observadas nas realidades servidas pela SME. A estrutura, pois, indica tanto um posicionamento filosófico e político quanto aspectos práticos do cotidiano escolar da rede municipal de Piracicaba, uma rede consolidada com ações e projetos efetivos que devem ser mantidos e com oportunidades para novos desafios exigidos das sociedades atuais. De modo especial, buscando atender a essas demandas, três aspectos político-sociais formam os pilares da ação educativa proposta pelo município para suas escolas: integralidade, equidade e inclusividade. Para tanto, os pactos entre as demais secretarias e com o próprio comprometimento do executivo municipal são fundamentais.

A Lei Orgânica do Município de Piracicaba (LOMP), atualizada em abril de 2018, entende e insere a educação em seu escopo de atuação. No artigo 252, compromete-se com a criação de condições para o desenvolvimento das potencialidades do educando, a integração da criança em seu meio e o desenvolvimento dos alunos para o exercício da cidadania. No artigo 253, busca claramente defender o pluralismo de ideias e de concepções pedagógicas.

O foco de atuação e os recursos necessários também estão definidos na legislação local, indicando que o município tem como prioridade o ensino pré-escolar de 0 a 6 anos, podendo 
atuar somente nos níveis mais elevados quando a demanda naquele nível estiver plena e satisfatoriamente atendida do ponto de vista qualitativo e quantitativo, com exceção das escolas ainda presentes nos demais níveis, os cursos já existentes na Fundação Municipal de Ensino, ou vier a atender ao ensino supletivo de portadores de deficiências ou de alfabetização de adultos e programas constantes nos centros educacionais municipais. O município deve aplicar, anualmente, na manutenção e no desenvolvimento do ensino público, no mínimo vinte e cinco por cento da receita resultante de impostos, incluindo recursos provenientes de transferências. É importante salientar que a cidade possui um Conselho Municipal de Educação, normativo, consultivo e deliberativo, com autonomia sobre o sistema educacional local.

A matriz curricular municipal foi construída de maneira horizontal e colaborativa, na contramão das políticas públicas educacionais de larga escala, alinhada à ideia de ecologia dos saberes. As instâncias executivas garantiram tempos e espaços para que os esforços das equipes, incluindo funcionários alocados na SME e funcionários públicos destinados às escolas municipais, em parceria com a Diretoria Regional de Ensino e a União dos Dirigentes Municipais de Ensino (Undime), pudessem concretizar-se em encontros formativos e de criação (dentro e fora do município).

O documento é opulento em suas sustentações teóricas e oportuniza aprender sobre as práticas pedagógicas a partir dos textos introdutórios para cada segmento e os componentes curriculares. Para a etapa da Educação Infantil, mais de cinquenta páginas tecem as diretrizes acerca da concepção de educação, de infância e de criança, a respeito de educar e cuidar, interações, brincadeiras e linguagens como princípios pedagógicos, a organização do dia a dia educativo, espaços, tempos e materiais, o protagonismo da família e do professor, o projeto político-pedagógico, a metodologia de projetos, a documentação pedagógica e a avaliação. Uma bricolagem de ideias bem ilustradas que merecem atenção e estudo - até mesmo para perceber o alinhamento de tais ideias com as práticas docentes.

A etapa do Ensino Fundamental apresenta reflexões sobre as características dos Anos Iniciais e a concepção de sujeito que embasa a formação, especificando os processos sobre os temas contemporâneos que perpassam pelas narrativas de ensino, tipos, finalidades e características dos processos de avaliação da aprendizagem e a continuidade dos estudos para a etapa seguinte. De maneira pragmática, a leitura dos textos introdutórios esclarece à toda a comunidade os planos de ações para a etapa. 
Por ser bastante detalhista em suas concepções, o currículo piracicabano nasce com mais de quinhentas páginas, na tentativa de abranger todos os pormenores de sua criação e, ao mesmo tempo, inserir as diretrizes pedagógicas. Seguindo os modelos de seus antecessores (BNCC e $\mathrm{CP}$ ), o longo formato inviabiliza a impressão em larga escala para estudo nas escolas (uma vez que a cópia impressa da matriz curricular ainda é imprescindível em face do formato exclusivamente digital). No entanto, contextualizar o documento histórico é primordial, e pensar em estruturas para agrupar textos introdutórios e pareceres anexos separadas dos quadros de orientação pode auxiliar no leiaute ergonômico.

Tratando especificamente dos impactos da BNCC no documento piracicabano, percebemos que as experiências dos profissionais da educação do município influenciaram fortemente as escolhas tanto em momentos em que optam por reproduzir a matriz nacional quanto nos pontos de ruptura. Um impacto importante que contribuiu para as discussões na SME foi a atenção dada pela BNCC ao processo de transição da Educação Infantil para o Ensino Fundamental. No município, o efeito causado foi o comprometimento de ações pensadas em conjunto por profissionais de ambos os segmentos, começando por conhecer a realidade da transição nas visões/percepções dos profissionais diretamente ligados ao processo.

De maneira concreta, o currículo municipal apresenta uma seção sobre a articulação entra a Educação Infantil e os Anos Iniciais do Ensino Fundamental, elencando as sínteses de aprendizagens a serem garantidas e o papel dos docentes na transição. Ainda como efeito prático, a matriz de Piracicaba inclui o espaço para "Experiências Lúdicas" na Matriz Curricular do primeiro ano com a intencionalidade didática de preservar a ludicidade, ou seja, conservar o uso de jogos e brincadeiras, da imaginação e da fantasia como fomentadores de aprendizagens; tal caráter próprio da natureza da Educação Infantil ganha destaque também no Ensino Fundamental.

Uma ruptura estratégica do currículo local foi a de apresentar às sociedades os referenciais teóricos do município: as escolhas implicam posicionamentos claros com relação às linhas e concepções educacionais privilegiadas pela equipe técnica e estão explicitadas nas bibliografias elencadas em cada seção do currículo. Por não conter referência bibliográfica, a Base criou a necessidade do engajamento teórico e da qualificação dos profissionais para fugir dos inúmeros debates sem fundamentos provocados, em parte, pelo governo federal e, em parte, pela mídia não especializada em educação, quando da divulgação da BNCC. Mesmo no campo 
da educação, muitos esforços foram feitos para explicar os referenciais teóricos e as ideias centrais da Base: uma série de vídeos sobre as competências gerais, documentos e infográficos - muitos deles financiados por fundações ou organizações não governamentais apoiadas por grandes grupos empresariais. É importante salientar que o currículo piracicabano se afasta de tais vínculos ao sustentar suas escolhas teóricas e embasar suas decisões técnicas.

$\mathrm{Na}$ escrita, outra ruptura de viés teórico-ideológico marcante acontece nas orientações das habilidades propostas. Para a Educação Infantil, muito embora a matriz piracicabana ainda considere as divisões dos campos de experiência em três grupos etários, os redatores optaram por parafrasear algumas habilidades da Base, conferindo significado outro ao texto original e/ou ignorando habilidades específicas sem atribuir novas habilidades correspondentes. Na Tabela 1, ilustramos alguns exemplos.

Tabela 1 - Comparação entre as propositivas da Base Nacional Comum Curricular [BNCC] e do currículo piracicabano

Eixo “O Eu, o Outro e o Nós” para Bebês (a 1 ano e 6 meses)

BNCC

Currículo Piracicabano (p. 94)

(EI01EO01) Perceber que suas ações têm efeitos nas outras crianças e nos adultos.

(EI01EO03) Interagir com crianças da mesma faixa etária e adultos ao explorar espaços, materiais, objetos, brinquedos.

(EI01EO05) Reconhecer seu corpo e expressar suas sensações em momentos de alimentação, higiene, brincadeira e descanso.
Perceber que, através das interações e das brincadeiras com outras crianças e adultos, constituem-se relações de amizade.

Interagir com crianças de mesma idade e idades diferentes, em variados espaços, explorando materiais não estruturados, brinquedos e recursos da natureza.

(Sem habilidade correspondente para a faixaetária no eixo.)

Fonte: Resultados originais da pesquisa.

Os currículos municipais têm autonomia sobre as matrizes estaduais e a BNCC, desde que expressem as mesmas normativas. Na Tabela 1, entendemos que a autonomia ainda se aplica, embora o texto piracicabano traga os entendimentos específicos da propositiva nacional. Para a habilidade (EI01EO01), o currículo da cidade situa o ato de perceber ("através das interações e das brincadeiras") e define seu efeito ("relações de amizade"). Ao fazer isso, especifica o comando para as ações docentes, mas pode ignorar outros atos e efeitos. $\mathrm{O}$ mesmo 
ocorre em (EI01EO03): insere-se a convivência com crianças de outras faixas etárias (ausente na matriz nacional), porém ignora a figura do adulto na habilidade em questão. Aqui ainda é possível perceber a linha teórica privilegiada pelo município ao incluir "materiais não estruturados" e "recursos da natureza" como elementos significativos interacionais. A habilidade (EI01EO05) não apresenta paridade no texto da cidade, por não corresponder a uma habilidade adequada para faixa etária dentro do campo de experiência proposto, na visão dos redatores, ou por estes entenderem que ela já está contemplada nos demais objetivos de aprendizagem. Independentemente da justificativa e/ou critérios para exclusão/adaptação das habilidades da BNCC para a matriz da cidade, eles não foram explicitados na longa introdução sobre a etapa da Educação Infantil.

Em outros momentos, as tabelas de habilidades no currículo municipal para Educação Infantil trazem em seu bojo orientações didático-metodológicas, no sentido de repertoriar os docentes, garantindo a uniformização das práticas. Observemos mais um exemplo na Tabela 2.

Tabela 2 - Orientações didático-metodológicas como objetivos de aprendizagem

Eixo "Espaços, Tempos, Quantidades, Relações e Transformações para Crianças Pequenas

\begin{tabular}{l}
\multicolumn{1}{c}{ BNCC } \\
\hline (EI03ET01) \\
Estabelecer \\
relações de \\
comparação entre \\
objetos, observando \\
suas propriedades.
\end{tabular}

(EI03ET03) Identificar e selecionar fontes de informações, para responder a questões sobre a natureza, seus fenômenos, sua conservação.
Currículo Piracicabano

Estabelecer relações de comparação entre objetos, observando suas propriedades. Por meio da exploração e da investigação, proporcionar experiências nas quais as crianças possam manipular, explorar, comparar, sequenciar e ordenar materiais, objetos e brinquedos, observando o peso, o tamanho e o volume de formas bidimensionais ou tridimensionais. Usar materiais, como argila, massa de modelar, por meio de construções e desconstruções.

Identificar e selecionar fontes de informações, para responder a questões sobre a natureza, seus fenômenos, sua conservação. As crianças pequenas aprendem sobre a natureza, seus fenômenos e sua conservação vivendo situações de exploração, de interação, de observação e de investigação sobre os elementos e fenômenos naturais. Formulam perguntas, levantam hipóteses e buscam fontes de informações para encontrar respostas e, assim, ampliar suas noções e enriquecer suas experiências, utilizando de diferentes estratégias para buscar informações, coletar dados e viver novas situações. É importante que tenham a oportunidade de observar e criar explicações para fenômenos e elementos da natureza presentes no seu dia a dia (calor produzido pelo sol, chuva, claroescuro, quente-frio), estabelecendo regularidades, relacionando-os à necessidade dos humanos por abrigo e cuidados básicos - agasalhar-se, não ficar exposto ao sol, beber líquido, fechar ou abrir janela, acender ou apagar a luz -, apontando algumas mudanças de hábitos em animais, ou plantas, influenciadas por mudanças climáticas, contribuindo para a aprendizagem de 
noções, habilidades e atitudes em relação à natureza, seus fenômenos e sua conservação.

Fonte: Resultados originais da pesquisa.

A Tabela 2 ilustra como os redatores deliberadamente orientam as práticas curriculares ao inserirem nos objetivos de aprendizagem as indicações de como tais objetivos devem ser buscados. Isso causa uma quebra do padrão anterior - o campo destinado aos objetivos de aprendizagem ganha nova função ao explicitar outros itens de orientação curricular. Comparando a Tabela 1 com a Tabela 2, que são exemplos que se estendem por toda a matriz piracicabana na Educação Infantil, percebemos informações e propósitos diferentes, o que pode indicar possível confusão no currículo entre o que são expectativas de aprendizagens na Educação Infantil e o que são as práticas pedagógicas a serem contempladas pelos professores durante essa etapa - ambas aparecem sob o mesmo título de objetivos de aprendizagem.

Para os Anos Iniciais do Ensino Fundamental, o currículo piracicabano apresenta sua estrutura a partir dos componentes curriculares, com progressão das habilidades e aprofundamento dos objetos de conhecimento, em consonância com a BNCC e o Currículo Paulista. O próprio documento, no entanto, aponta para as modificações, os desmembramentos e a criação de novas habilidades de modo a atender às especificidades do município. Na Tabela 3, a seguir, elencamos alguns exemplos dos descritores.

Tabela 3 - Criação e modificação de habilidades no currículo de Piracicaba

\begin{tabular}{ll}
\hline \multicolumn{1}{c}{ BNCC } & \multicolumn{1}{c}{ Currículo Piracicabano } \\
\hline $\begin{array}{l}\text { (Sem habilidade correspondente para a faixa etária } \\
\text { no eixo) }\end{array}$ & $\begin{array}{l}\text { (EF02EF15SME) Protagonizar situações e } \\
\text { formular estratégias para ampliar as } \\
\text { possibilidades de aprendizagem de brincadeiras } \\
\text { e jogos populares incluindo aqueles da cultura } \\
\text { regional e tirolesa. }\end{array}$ \\
$\begin{array}{l}\text { (EF01MA07) Compor e decompor número de até } \\
\text { duas ordens, por meio de diferentes adições, com o } \\
\text { suporte de material manipulável, contribuindo para }\end{array}$ & $\begin{array}{l}\text { (EF01MA07*) Compor e decompor um número } \\
\text { natural (princípio aditivo) com o suporte de } \\
\text { a compreensão de características do sistema de } \\
\text { numeração decimal e o desenvolvimento de manipuláveis. } \\
\text { estratégias de cálculo. }\end{array}$ \\
\hline
\end{tabular}
Fonte: Resultados originais da pesquisa.

A Tabela 3 indica que o currículo piracicabano inclui a cultura regional e especifica a cultura tirolesa na realocação dos saberes que não encontram correspondência na guia curricular 
nacional. No outro exemplo, a habilidade específica de Matemática para o primeiro ano não é tão específica quanto a da Base em relação às ordens dos números (dezena, centena etc.) e sinaliza um modo (princípio aditivo) de fazer composição/decomposição, ainda sem mencionar o contexto ou o propósito da habilidade original (sistema de numeração decimal e estratégias diferentes de cálculo).

As escolhas dos redatores não são ingênuas e carregam posicionamentos políticos no campo das correntes curriculares. A visão sobre um currículo mais prescritivo é criticada por limitar as ações docentes ao que está estritamente disposto no documento. Por outro lado, currículos prescritivos, como o de Piracicaba, têm efeito em redes por garantirem a uniformização das práticas pedagógicas privilegiadas no documento curricular. Ressaltamos, pois, a ênfase na formação dos profissionais da educação perante os entendimentos teóricos que os quadros representam e a construção conjunta dos planos de ensino que surgirão a partir do currículo. Por fim, assinalamos, conforme escreve Saviani (2016), que a organização curricular deverá tomar como referência as formas de organizações das sociedades atuais, assegurando sua plena compreensão por parte de todos os educandos.

\section{DISCUSSÃO}

“Tudo o que é sólido se desfaz no ar." Com esse título, o sociólogo português Boaventura de Sousa Santos abre seu livro A cruel pedagogia do vírus, escrito e lançado este ano em meio à pandemia da Covid-19 (sigla em inglês para Corona Virus Disease). Faço uso da mesma alegoria para inserir aqui algumas considerações, feitas após a escrita da conclusão, que buscam ressignificar as ideias apresentadas.

Qual currículo nos prepararia para este momento - no qual o estado de exceções é a normalidade, no qual profissionais da saúde escolhem os que devem ser salvos? Que tipo de educação nos prepara para os momentos em que nos entendemos iminentemente frágeis? O programa desenhado para Piracicaba será eficaz no desenvolvimento dos estudantes para cumprirem seus papéis sociais em cenários incertos?

Por mais provocativos e retóricos que possam parecer, tais questionamentos retomam o propósito social do ato educativo. Historicamente, o processo educacional dos indivíduos nas sociedades reforça a identificação do indivíduo com as tradições nacionais, a cidadania voltada ao nacionalismo e a homogeneidade. Tais implicações que perduram ainda hoje têm dimensões 
públicas para além de promover o desenvolvimento do sujeito. A educação, em seu aspecto político, regula a dialética de formar indivíduos para o coletivo. Na dimensão econômica, tenta balancear a equação custo-benefício, enquanto os estados assumem postura de investidores educacionais para obterem retorno econômico.

O Programa Internacional de Avaliação de Estudantes (PISA), em seu caráter políticoeconômico, alimenta-se das incertezas que temos sobre o futuro: nossos jovens serão bemsucedidos e contribuirão com membros da sociedade? O que está em risco é muito mais do que o controle ou a legitimação do que é conhecimento; trata-se de visão etnocêntrica - racista por vezes - de encarar o mundo. As implicações ultrapassam a área educacional e atingem a área social, por meio de políticas como a que faz com que famílias percam parte de sua renda dada pelo estado, se o filho falta à escola. A consequência é uma tendência de homogeneização global da educação e a instauração de modelos educacionais autoritários que privilegiam determinados comportamentos humanos enquanto desqualificam outros atributos e culturas.

A pandemia, tal como a educação, não é democrática, ou seja, não atinge a todos da mesma forma. E tanto na educação quanto na pandemia os grupos invisibilizados são os mesmos. A diferença abissal permanece entre os grupos sociais no setor educacional; as escolas que servem sociedades com maior capital encontram superficial tranquilidade na manutenção dos processos de ensino-aprendizagem mediados remotamente, enquanto as redes e sistemas públicos municipais e estaduais adiantam-se em manter cuidados básicos de sobrevivência, garantindo a alimentação dos alunos em casa, por exemplo, em função de falta de estruturas próprias que viabilizassem práticas pedagógicas remotas.

Por conseguinte, respondendo - ainda que minimamente - às provocações, o tipo de educação oferecida não deve ser desvinculado de uma política de promoção do que Boaventura chama de justiça cognitiva, tão bem estruturada quanto a justiça social que já prevalece (ao menos na Constituição brasileira, com o Estado de Bem-Estar Social, nos ideais de John Rawls). Em outras palavras, é preciso educar para que os conhecimentos produzidos pela humanidade, em sentido horizontal, formando um sistema plural de saberes, cheguem a todos para o combate à extrema desigualdade social e à destruição da vida do planeta.

Enfim, o que aprendemos com a pandemia até aqui? Que já vivíamos uma situação de não normalidade para muitos grupos sociais? Que o combate à pobreza e a mobilização social devem permear as intencionalidades educacionais? Que da preservação dos recursos naturais 
dependem todas as vidas no planeta? Aprendemos, ou reaprendemos, o que numa perspectiva mais ampla - e poética - Paulo Freire (1993), em períodos tão simples e diretos como estes, nos alertava: o amanhã vira o hoje, repetindo-se, violento e perverso - o hoje do ontem; justifica-se, portanto, a rigorosa "leitura de mundo", a necessidade da competência científica que deve estar sempre a serviço de algo e de alguém, de grupos populares invisibilizados, "demitidos da vida". Assim, entendemos que o currículo municipal deve servir a todos, principalmente explorados e oprimidos cujas identidades lhes foram expropriadas.

\section{CONCLUSÃO}

Com o cuidado de não sermos exaustivos, procuramos expor os principais impactos da criação de uma matriz normativa nacional comum e perceber suas representações e releituras nas concepções de um documento normativo local. O currículo da rede municipal de Piracicaba (CRMP) repete o formato do $\mathrm{CP}$, que por sua vez repete a BNCC em sua macroestrutura (competências gerais, competências específicas, campos de experiência por faixa etária na educação infantil e habilidades por componentes curriculares seriados nos Anos Iniciais do Ensino Fundamental, com atenção especial às fases de transição - do Infantil aos Anos Iniciais, dos Anos Iniciais aos Anos Finais). O município, no entanto, segue com as prerrogativas de não apresentar fidelidade total na correspondência das habilidades, uma vez que, para os saberes fazerem sentido para as comunidades servidas pelas escolas de Piracicaba, os objetivos de aprendizagem precisam ser relocalizados e contextualizados. Uma característica forte das reformas educacionais no Brasil - das quais BNCC e CP são bons exemplos - é negligenciar a formação docente. Em Piracicaba, a ideia de incluir professores desde o momento zero da criação do documento é a aposta para que em 2020 o currículo fosse implementado com sucesso. Isso também depende de inúmeros esforços formativos, ainda sem a parceria concreta dos institutos superiores de formação de docentes da cidade e região. Os programas defasados nas licenciaturas não dão conta de preparar o educador para as realidades dos cenários da educação no País, ou mesmo para as aspirações dos novos currículos. As iniciativas de mudanças na educação que ignoram a preparação de professores são condenadas ao fracasso na medida em que não dão atenção ao conhecimento e às habilidades dos principais agentes de mudanças, sem os quais pouca transformação é possível (FULLAN, 2014). O terceiro pilar de 
impacto - além do currículo sólido e de educadores capazes e preparados - é o suporte de ferramentas e o amparo tecnológico que possibilitam novas aprendizagens, facilitam a investigação e a pesquisa, as interações humanas e podem trazer oportunidades equitativas. Retomamos assim os objetivos da presente pesquisa que respondeu à seguinte pergunta investigativa: quais os impactos da BNCC na construção de um currículo local. A partir de então, como os três pontos levantados sugerem (currículo, formação docente e processos de implantação), é papel dos gestores otimizar a implantação com uso de tecnologias, alocando recursos de forma eficiente e, principalmente, na capacitação docente em serviço.

\section{REFERÊNCIAS}

ADORNO, Theodor W. Educação e emancipação. Rio de Janeiro: Paz e Terra, 1995.

APPLE, Michael W. Ideologia e currículo. São Paulo: Brasiliense, 1982.

AUSUBEL, David P. The acquisition and retention of knowledge: a cognitive view. New York: Kluwer Academic Publishers, 2000.

BAKHTIN, Mikhail M. Estética da criação verbal. 6. ed. São Paulo: Martins Fontes, 2011.

CAMPOS, Rosânia; BARBOSA, Maria Carmen S. BNC e educação infantil: quais as possibilidades? Retratos da Escola, Brasília, v. 9, n. 17, p. 353-366, 2015. Disponível em: http://retratosdaescola.emnuvens.com.br/rde/article/view/585. Acesso em: 23 maio 2019.

BOURDIEU, Pierre. O poder simbólico. Rio de Janeiro: Bertrand Brasil, 1989.

BRASIL. Base Nacional Comum Curricular. 3. ${ }^{a}$ versão revista. Brasília: Ministério da Educação, 2017. Disponível em:

basenacionalcomum.mec.gov.br/images/BNCC_publicacao.pdf. Acesso em: 8 ago. 2019.

CAMPOS, Maria M. Balanço analítico da educação infantil: direitos em risco e consensos possíveis. 38. ${ }^{a}$ Reunião Nacional ANPEd. São Luís, 2017.

DAVIS, Cláudia; OLIVEIRA, Zilma R. Psicologia na educação. 2. ed. SãoPaulo: Cortez, 1994.

DEWEY, John. Democracia e educação: introdução à filosofia da educação. Tradução

Godofredo Rangel e Anísio Teixeira. 3. ed. São Paulo: Nacional, 1959.

FREIRE, Paulo. Política e educação. São Paulo: Cortez, 1993.

FREITAS, Luís Carlos. Os reformadores empresariais da educação e a disputa pelo controle do processo pedagógico na escola. Educação e Sociedade, v. 35, n. 129, p. 1085-1114, 2014. 
Disponível em: https://www.scielo.br/pdf/es/v35n129/0101-7330-es-35-129-01085.pdf. Acesso em: 14 dez. 2018.

FULLAN, Michael. The principal. São Francisco: Jossey-Bass, 2014.

GATTI, Bernadete A.; BARRETO, Elba S.S.; ANDRÉ, Marli Elisa D. A.; ALMEIDA, Patrícia Cristina A. Professores do Brasil: novos cenários de formação. Brasília: UNESCO, 2019. Disponível em: https://www.fcc.org.br/fcc/wpcontent/uploads/2019/05/Livro_ProfessoresDoBrasil.pdf. Acesso em: 23 mar. 2019.

HEUDEGGER, Martin. Ser e tempo. 2. ed. Petrópolis: Vozes, 2007.

KRAMER, Sonia. As crianças de 0 a 6 anos nas políticas educacionais no Brasil: educação infantil e ensino fundamental. Educação e Sociedade, Campinas, v. 27, n. 96, p. 797-818, 2006. Disponível em: https://www.scielo.br/pdf/es/v27n96/a09v2796.pdf. Acesso em: 17 mar. 2019.

MACEDO, Elizabeth. Base Nacional Curricular Comum: novas formas de sociabilidade produzindo sentidos para educação. e-Curriculum, v. 12, n. 3, p. 1530-1555, 2014.

Disponível em: https://revistas.pucsp.br/index.php/curriculum/article/view/21666. Acesso em: 20 abr. 2019.

PIMENTEL, Alessandra. O método da análise documental: seu uso numa pesquisa historiográfica. Cadernos de Pesquisas, Londrina, n. 114, p. 179-195, 2001. Disponível em: https://www.scielo.br/pdf/cp/n114/a08n114.pdf. Acesso em: 11 nov. 2018.

PIRACICABA. Plano Municipal de Educação. Secretaria Municipal de Educação, 2016. Disponível em: educacao.piracicaba.sp.gov.br/wp-content/uploads/2017/04/Clique-aqui1.pdf. Acesso em: 30 mar. 2018.

PIRACICABA. Currículo da rede municipal. Secretaria Municipal de Educação, 2019.

RAWLS, John. Uma teoria da justiça. São Paulo: Martins Fontes, 2008.

SANTOS, Boaventura S. A gramática do tempo: para uma nova cultura política. São Paulo: Cortez, 2006.

SANTOS, Boaventura S. A cruel pedagogia do vírus. Coimbra: Almedina, 2020.

SÃO PAULO. Currículo Paulista. São Paulo: Secretaria Estadual de Educação, 2019.

SAVIANI, Demerval. Escola e democracia. Autores Associados. São Paulo: Cortez, 1983.

SAVIANI, Demerval. Educação escolar, currículo e sociedade: o problema da base nacional comum curricular. Revista Movimento, ano 3, n. 4, p. 54-84, 2016. 
SILVA, Tomaz. T. Documentos de identidade: uma introdução às teorias do currículo. Belo Horizonte: Autêntica, 1999.

\section{NOTAS}

1 Dados da SME, disponíveis em: http://educacao.piracicaba.sp.gov.br/dados-estatisticos/. Acesso em: 8 abr. 2020.

2 Para saber mais sobre o cálculo do Ideb, leia a Nota Técnica do MEC disponível em: http://download.inep.gov.br/educacao_basica/portal_ideb/o_que_e_o_ideb/Nota_Tecnica_n1_concepcaoIDEB.p df. Acesso em: $1^{\circ}$ maio 2020.

${ }^{3}$ Disponível em: http://educacao.sobral.ce.gov.br/downloads. Acesso em: 20 fev. 2020.

Recebido em: 26/08/2020

Aprovado em: 19/11/2020 